Priscila Matos Resinentti

\title{
QUALIDADE EDUCACIONAL DA REDE MUNICIPAL DO RIO DE JANEIRO: É POSSÍVEL PERCEBÊ-LA NO ENSINO DE CIÊNCIAS?
}

Dissertação apresentada como requisito parcial para obtenção do grau de Mestre pelo Programa de Pós-Graduação em Educação do Departamento de Educação da PUC-Rio.

Orientador: Profa ${ }^{a}$. Fátima Cristina de Mendonça Alves 


\section{QUALIDADE EDUCACIONAL DA REDE MUNICIPAL DO RIO DE JANEIRO: É POSSÍVEL PERCEBÊ-LA NO ENSINO DE CIÊNCIAS?}

Dissertação apresentada como requisito parcial para obtenção do grau de Mestre pelo Programa de Pós-Graduação em Educação do Departamento de Educação do Centro de Teologia e Ciências Humanas da PUC-Rio. Aprovada pela Comissão Examinadora abaixo assinada.

Prof ${ }^{a}$. Fatima Cristina de Mendonça Alves

Orientadora

Departamento de Educação - PUC-Rio

Profe. Cynthia Paes de Carvalho

Departamento de Educação - PUC-Rio

Profa. Marcia Serra Ferreira Faculdade de Educação - UFRJ

Profa. Denise Berrenzo Portinari Coordenadora Setorial do Centro de Teologia e Ciências Humanas

Rio de Janeiro, 03 de abril de 2012. 
Todos os direitos reservados. É proibida a reprodução total ou parcial do trabalho sem autorização da universidade, da autora e do orientador.

Priscila Matos Resinentti

Graduou-se em Ciências Biológicas pela Universidade Federal do Rio de Janeiro (UFRJ) em 2006. Atua nas redes municipal e privada nas séries finais do Ensino Fundamental e no Ensino Médio. Desde 2011 participa do Observatório Educação e Cidade da PUC-Rio, estudando temas na área de Políticas Educacionais, Qualidade da Educação e Avaliação.

Ficha Catalográfica

Resinentti, Priscila Matos

Qualidade educacional da rede municipal do Rio de Janeiro: é possível percebê-la no ensino de ciências? / Priscila Matos Resinentti ; orientadora: Fatima Alves. - 2012.

155 f. : il. (color.) ; 29,7 cm

Dissertação (Mestrado)-Pontifícia Universidade Católica do Rio de Janeiro, Departamento de Educação, 2012. Inclui bibliografia

1. Educação - Teses. 2. Qualidade da educação. 3. Ensino de ciências. 4. Políticas públicas. 5. Avaliação. 6. Rede municipal do Rio de Janeiro. I. Alves, Fatima. II. Pontifícia Universidade Católica do Rio de Janeiro. Departamento de Educação. III. Título. 
Para Deus, meus pais, meu irmão e meu marido.

Sem vocês não teria conseguido! 


\section{Agradecimentos}

Qualquer palavra que expresse afeto será pouca diante da gratidão e amor que tenho por Deus. A maneira de agradecer tudo o que Ele fez, faz e fará em minha vida é ser fiel a sua palavra pra sempre e fazer o melhor pra Deus onde eu estiver! Desde pequena aprendi a confiar em Deus porque Ele nos abençoa de oração em oração, de obediência em obediência e de louvor em louvor. Por isso, glorifico o nome Dele através de um versículo que eu vivi intensamente desde o momento em que sonhei fazer parte do Programa de Pós-graduação em Educação da PucRio e conquistar o título de mestre: "Porque não me envergonho do evangelho de Cristo, pois é o poder de Deus para salvação de todo aquele que crê. Porque nele se descobre a justiça de Deus de fé em fé, como está escrito: Mas o justo viverá da fé”. Romanos 1:16-17

Aos meus amados pais, Edilde e Luiz, e meu irmão, Luiz, pelo amor, carinho, admiração, compreensão e apoio constantes. Vejo em meus pais exemplos a serem seguidos: respeito, dedicação e honestidade. Vocês me ensinaram a lutar pelos meus sonhos. Em meu irmão, tenho um grande amigo que sabe me fazer sorrir nos momentos mais difíceis. Vocês são bênçãos de Deus em minha vida. Amo vocês!

Ao meu amado marido, Luiz Eduardo, por estar ao meu lado incondicionalmente, por viver os meus sonhos, por toda a paciência, amor e incentivos dados. Por ter compreendido as minhas "ausências" todas as vezes que precisei doar tempo aos estudos para a conclusão desse curso e me motivar nos momentos mais desafiadores. Obrigada por não ter desistido de me conquistar desde o dia em que Deus cruzou as nossas histórias para convertê-la em uma só. Eu tenho profunda gratidão ao Senhor por ter colocado um homem de fé e caráter ao meu lado para edificar a nossa casa e, juntos com Deus, construirmos uma linda família. Amo, amo, amo você! 
Aos demais familiares, "Resinentti e Fleischner", e amigos muito especiais pela torcida, incentivo, palavras de ânimo e orações. Especialmente à minha sogra, padrinhos e madrinhas de casamento e amigas queridas do Fundão (Ana Claudia, Caroline, Fernanda, Flávia e Raquel). Vocês são parte fundamental da minha história!

À minha orientadora, Fatima Alves, por compartilhar tanto conhecimento e palavras de apoio. Sempre esteve pronta a ajudar para que eu não desistisse a cada mudança de rumo na construção dessa pesquisa. Obrigada pelas oportunidades de crescimento e pelo privilégio de ter uma orientadora tão competente, determinada e alegre! Não posso esquecer-me da sua pequena Elizabethe, que me fez rir tantas vezes quando me orientou em sua casa, deixando o trabalho mais leve.

Aos professores e amigos do grupo de pesquisa Observatório Educação e Cidade pelas discussões sobre desigualdade educacional, pelos conhecimentos partilhados e pelas divertidas e intensas tardes de trabalho no São Marcelo. Especialmente, agradeço à Adailda Gomes, ao André Regis e à Marcela Brandão que acompanharam bem de perto essa pesquisa e ajudaram muito com palavras e gentilezas.

Às professoras Cynthia Paes de Carvalho e Alicia Bonamino pelas sugestões dadas ao meu projeto e grandes contribuições para o crescimento acadêmico.

Aos demais professores do Departamento de Educação da PUC-Rio que colaboraram com a minha formação, especialmente Marcelo Andrade, Maria Inês e Rosália Duarte.

Às professoras Marcia Serra Ferreira e Maria Margarida Gomes, que foram as responsáveis pela minha inserção na pesquisa educacional e pelo carinho de sempre a cada encontro.

À Dani Valla e Diego pela amizade e pelo empréstimo dos documentos/livros da rede pública para a minha análise. 
À CAPES e PUC-Rio pelo fomento à pesquisa e colaboração no meu aperfeiçoamento profissional.

À Secretaria Municipal de Educação pelo fornecimento dos dados quantitativos.

Aos amigos da minha turma de mestrado pelas conversas sobre educação e risadas também, especialmente a Naira! Aos doutorandos que partilharam conosco algumas disciplinas e contribuíram profundamente nos debates durante as aulas, especialmente Sergio Oscar e Marcela Guedes.

Aos pastores e amigos da Catedral Metodista do Rio de Janeiro pelas constantes orações e gestos de solidariedade.

Aos amigos e professores da Escola Municipal Engenheiro João Thomé pela força dada. Em especial, às diretoras Maria Aparecida e Jane por viabilizarem o meu horário para que eu conseguisse dar aula em Padre Miguel e cursar as matérias do mestrado na Gávea. Sempre me apoiaram! E, à Marta, pelo empréstimo dos documentos/livros da rede.

Aos amigos e professores do Colégio Batista Shepard pela torcida!

Para todos os alunos brasileiros, merecedores de uma educação de qualidade, e para todos os docentes que, a cada dia, lutam para construí-la. Em especial, aos meus queridos alunos pelos momentos de emoção, o que me faz ter certeza de que eu fiz a escolha certa.

A todos que de alguma forma fizeram parte da minha caminhada até aqui. 


\section{Resumo}

Resinentti, Priscila Matos; Alves, Fátima Cristina de Mendonça. Qualidade educacional da Rede Municipal do Rio de Janeiro: é possível percebê-la no ensino de ciências? Rio de Janeiro, 2012, 155p. Dissertação de Mestrado - Departamento de Educação, Pontifícia Universidade Católica do Rio de Janeiro.

A qualidade da educação é tema atual e muito discutido no cenário das políticas públicas que visam garanti-la. No entanto a qualidade do ensino de ciências medida através de avaliações ainda é novidade entre os municípios brasileiros, por isso esse estudo trata da iniciativa tomada pela Secretaria Municipal de Educação do Rio de Janeiro (SME). Inicialmente, o estudo apresenta a história do ensino de ciências no Brasil a partir da década de 1940 e, em seguida, aborda os aspectos ligados à história do ensino de ciências na rede municipal do Rio de Janeiro, enfatizando os contextos políticos e pedagógicos. De forma complementar, discute-se a temática da qualidade da educação e sua busca pela Rede Municipal do Rio de Janeiro, relatando-se as ações políticas e seus referenciais teóricos. Examinam-se os materiais disponibilizados na rede em 2010 e 2011, e também o perfil das provas aplicadas, avaliando-se as modificações ocorridas nesse período, bem como as perspectivas da Rede para o ensino de ciências. Complementarmente, apresentam-se os resultados alcançados nas escolas, tanto no IDERio 2010 quanto nas Provas da Rede de ciências, percebendo os possíveis impactos dos recursos de infraestrutura da escola, das atividades complementares, da formação do corpo docente e do IDS no desempenho das escolas. Conclui-se que a qualidade do ensino de ciências, tendo como foco o desempenho nas avaliações, ainda deixa a desejar. Mas, é perceptível o esforço da SME em estruturar didaticamente o ensino de ciências, com vistas a alcançar a melhoria na qualidade do mesmo.

\section{Palavras-chave}

Qualidade da educação; Ensino de Ciências; Políticas públicas; avaliação; rede municipal do Rio de Janeiro. 


\section{Abstract}

Resinentti, Priscila; Alves, Fátima. (Advisor). Educational quality of the Municipal Network of Rio de Janeiro: is it possible to perceive it in the science education? Rio de Janeiro, 2012, 155p. MSc. Dissertation Departamento de Educação, Pontifícia Universidade Católica do Rio de Janeiro.

The quality of education is a current topic and much discussed in the scenario of the public policies that aim to guarantee it. However, the quality of the science education being measured through assessments is still novelty among the Brazilian municipalities, so this study is about the initiative taken by the Municipal Education Secretariat of Rio de Janeiro (SME). At first, the study presents the history of the science education in Brazil from the1940s and then explores the aspects related to the history of the science education in the city of Rio de Janeiro, emphasizing the political contexts and teaching. In a supplementary way, it discusses the issue of the quality in education and the search of it by the Municipal Network of Rio de Janeiro, reporting the political actions and their theoretical frameworks. The materials available on the network in 2010 and 2011 are examined, and also the profile of the tests applied, evaluating the changes that occurred during this period, as well as the prospects of the Network for the science education. In addition, the results achieved in the schools are presented, both in the IDERio 2010 as in the science tests of the Network, perceiving the possible impacts of the infrastructure resources of the school, of the complementary activities, of the training of the teaching staff and of the IDS in the performance of schools. The conclusion is that the quality of the science education, focusing the performance on the evaluations, still leaves much to be desired. But it is noticeable the effort of SME in structuring didactically the science education, expecting the improvement in its quality.

\section{Keywords}

Education quality; Science Education; Public policies; evaluation; Municipal Network of Rio de Janeiro. 


\section{Sumário}

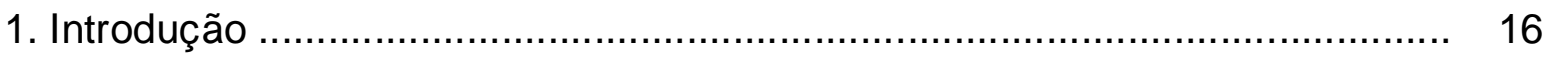

2. Os textos e os contextos do ensino de Ciências ........................................ 27

2.1. Uma breve contextualização histórica: O ensino de ciências de 1940 até os dias atuais

2.2. O ensino e as ações político-pedagógicas em ciências na Rede Municipal do Rio de Janeiro

3. A busca pela qualidade da educação no município do Rio de Janeiro: ações políticas e referenciais teóricos

4. A Metodologia

4.1. Qualitativa: Análise documental dos materiais disponibilizados a partir de 1978 gestão, incluindo desde as políticas/resoluções e análise dos materiais pedagógicos

4.2. Quantitativa: Descrição de fatores e características escolares, dos docentes e do desempenho das escolas municipais que atendem ao segundo segmento

5. Análise dos materiais pedagógicos da rede - tecendo similaridades e diferenças organizacionais

5.1. As Orientações Curriculares 79

5.2. O livro didático de 2010 86

5.3. Os cadernos pedagógicos em 2010 90

5.4. As provas de ciências do sétimo ano de 2010 e seus descritores 92

5.5. A análise transversal dos materiais

6. Apresentação da estrutura da Rede Municipal de Educação do Rio de Janeiro e análise dos recursos de infraestrutura, dos programas e atividades complementares, do perfil docente e os desempenhos no IDERio e em ciências (2010): tecendo relações entre as ações políticas e as (des)igualdades escolares

6.1. Análise da infraestrutura da Rede

6.2. Análise das atividades complementares da Rede 
6.3. Perfil e condições de trabalho dos docentes ........................................ 130

6.4. O desempenho no IDERio: tecendo relações .......................................... 134

6.5. O desempenho em Ciências: tecendo relações ....................................... 138

7. Considerações Finais ......................................................................... 144

8. Referências Bibliográficas ............................................................. 148

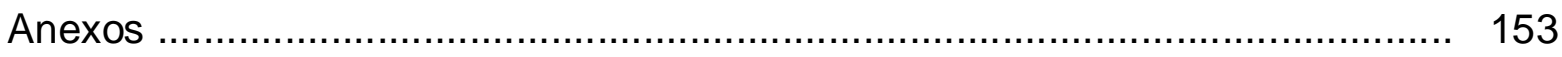




\section{Lista de Tabelas e Quadros}

Tabela 1: Número médio de alunos por escola em cada CRE ................. 121

Tabela 2: Quantitativo dos recursos de infraestrutura na Rede ................ 122

Tabela 3: Comparação entre os intervalos do IDERio 2010 e a quantidade de recursos de infraestrutura na escola

Tabela 4: Comparação entre a meta do IDERio e a presença de atividades complementares na escola

Tabela 5: Comparação entre os intervalos do IDERio 2010 e a presença de atividades complementares na escola

Tabela 6: Comparação entre os intervalos do IDERio 2010 e o IDS

Tabela 7: Comparação entre os intervalos do IDERio e a quantidade de atividades complementares nas escolas da rede

Tabela 8: Comparação entre os intervalos do IDERio e o vínculo ao Programa Escolas do Amanhã

Tabela 9: Comparação entre o alcance da média 5,0 na prova de ciências do $1^{\circ}$ bimestre e a quantidade de recursos de infraestrutura

Tabela 10: Comparação entre o alcance da média 5,0 na prova de ciências do $4^{\circ}$ bimestre e a quantidade de recursos de infraestrutura

Tabela 11: Comparação entre o alcance da média 5,0 na prova de ciências do $1^{\circ}$ bimestre e a presença de laboratório de ciências

Tabela 12: Comparação entre o alcance da média 5,0 na prova de ciências do $1^{\circ}$ bimestre e a presença de laboratório de ciências

Tabela 13: Comparação entre o alcance da média 5,0 na prova de ciências no $1^{\circ}$ bimestre e a presença de atividade complementar de ciências

Tabela 14: Comparação entre o alcance da média 5,0 na prova de ciências no $4^{\circ}$ bimestre e a presença de atividade complementar de ciências

Tabela 15: Comparação entre o alcance da média 5,0 nas provas de ciências no $1^{\circ}$ bimestre e o IDS

Tabela 16: Comparação entre o alcance da média 5,0 nas provas de ciências no 4 - bimestre e o IDS

Tabela 17: Distribuição de laboratório de ciências entre as faixas de IDS.

Quadro 1: Os objetivos do Ensino de Ciências. Fonte: SMEC/RJ,1978 ....

Quadro 2: Os objetivos do Ensino de Ciências. Fonte: SMEC/RJ,1978 .... 39

Quadro 3: Como ensinar Ciências. Fonte: SMEC/RJ,1978 ..................... 39

Quadro 4: Fontes utilizadas na análise qualitativa ................................ 72

Quadro 5: Variáveis da base de escolas do município do Rio de Janeiro 73 
que atendem ao segundo segmento do ensino fundamental

Quadro 6: Variáveis da base de docentes do município do Rio de Janeiro 76

Quadro 7: Princípios educativos / núcleos conceituais. Fonte:

Multieducação - Núcleo Curricular Básico, 1996

Quadro 8: O ensino de Ciências. Fonte: Secretaria Municipal de Educação. Multieducação: Rio de Janeiro, 2008. (Série Temas em Debate)

Quadro 9: Mapas Conceituais de Ciências por série. Fonte: Secretaria Municipal de Educação. Orientações Curriculares: Áreas Específicas. Rio de Janeiro, 2009

Quadro 10: Análise transversal dos materiais didáticos disponibilizados em 2010

Quadro 11: Análise transversal dos materiais didáticos disponibilizados em 2011

Quadro 12: Distribuição das escolas que atendem ao $2^{\circ}$ segmento e divisão das CREs

Quadro 13: Descritores das provas do $3^{\circ}$ bimestre/7ํㅡㄹ ano. Fonte: SME, 


\section{Lista de Gráficos, Figuras e Mapas}

Gráfico 1: Distribuição dos recursos de infraestrutura na Rede .............. 122

Gráfico 2: Distribuição dos recursos de infraestrura por CRE ................ 123

Gráfico 3: Quantidade de atividades complementares nas escolas ......... 125

Gráfico 4: Distribuição das atividades complementares disponíveis na rede nas escolas

Gráfico 5: Distribuição do Programa Escolas do Amanhã nas CREs ........

Gráfico 6: Quantidade de escolas que os docentes da cidade do Rio de Janeiro atendem

Gráfico 7: Distribuição dos docentes da cidade do Rio de Janeiro nas dependências administrativas

Gráfico 8: Quantidade de escolas que os docentes do $7^{\circ}$ ano atuam na rede municipal do Rio de Janeiro

Gráfico 9: Distribuição dos docentes do $7^{\circ}$ ano que atuam no município do Rio de Janeiro nas dependências administrativas

Gráfico 10: Desempenho das CREs no IDERio 2009 e IDERio 2010

Gráfico 11: Desempenho anual das CREs nas Provas da Rede de ciências em 2010

Figura 1: Ações do Programa Reforço Escolas. Fonte: SME, 2011

Figura 2: Os cinco reinos e suas características. Fonte: Projeto Araribá Ciências, 2006

Figura 3: Aspectos das novas Orientações Curriculares. Fonte: SME, 2012

Figura 4: Proposta para as novas Orientações Curriculares do ensino de ciências. Fonte: SME, 2011

Figura 5: Pilares do Programa Escolas do Amanhã. Fonte: SME, 2011 ...

Figura 6: Síntese da análise do desempenho das escolas no IDERio .......

Figura 7: Síntese da análise sobre o desempenho em ciências

Mapa 1: Limites das CREs

Mapa 2: IDS das escolas e das CREs

Mapa 3: Distribuição dos setores subnormais pelos limites das CREs ...

Mapa 4: Distribuição dos recursos de infraestrura

Mapa 5: Distribuição das atividades complementares

Mapa 6: Desempenho das escolas na prova de ciências do $1^{\circ}$ bimestre .. 139

Mapa 7: Desempenho das escolas na prova de ciências do 4ํㅡㅁimestre .. 
“A educação é um processo social, é desenvolvimento. Não é a preparação para a vida, é a própria vida." John Dewey 